\title{
A CASE OF OPHTHALMOPLEGIC MIGRAINE
}

\author{
Lt Col S ROHATGI ${ }^{*}$, Lt Col HS BHATOE ${ }^{+}$
}

MJAFI 1999; 55 : 356

KEY WORDS: Migraine; Ophthalmoplegia.

\section{Introduction}

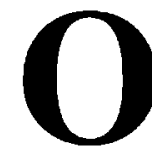

phthalmoplegic migraine is a well known entity, although it is rarely seen in clinical practice. It can occur for the first time in a background of common or classical migraine or it may develop de novo. It may occur in infancy [1] but onset in fourth and fifth decade can occur. Recurrent episodes are common. The resulting neurological deficit has often led to detailed investigations including angiography to rule out aneurysms of posterior communicating artery or internal carotid artery. We report a case of ophthalmoplegic migraine in a soldier.

\section{Case Report}

A 42-year-old soldier developed diplopia following exposure to smoke and fumes of enemy artillery shelling in a forward location. Diplopia was maximum in down gaze on looking towards right side. Same day at night he developed intense throbbing headache localised to left fronto temporal location. He also had vomiting and photophobia. Later the intensity of headache decreased and it became dull ache. He was admitted to a service hospital where clinical exam revealed partial ptosis, exotropia, weak adduction, supra and infraduction of left eye. Left pupil was semidilated and sluggishly reacting to light. There was no other neurological deficit. Systemic examination was unremarkable. He was transferred to this hospital for further investigations. On arrival at this hospital patient was conscious and oriented. Temporal artery pulsations were normal. He had left sided oculomotor nerve palsy with pupillary involvement. Fundus was normal and vision was $6 / 6$ both eyes. There were no signs of meningeal irritation. He denied any past history of similar symptoms or history suggestive of migraine.

ESR-26 mm fall. Other haematological and biochemical parameters were normal. X-Ray chest-NAD. Blood STS-Non reactor. HIV negative by ELISA method.

Initial diagnosis was aneurysm in Left posterior communicating artery. A CECT brain was done, which was normal. A left carotid angiogram was performed which was also normal. Patient was then diagnosed as a case of ophthalmoplegic migraine. He responded to NSAIDS and was put on prophylaxis with amytryptiline, flunarzine and cyproheptadine and has completely recov- ered from oculomotor nerve palsy.

\section{Discussion}

Ophthalmoplegic migraine was originally described by Symonds [2]. Migraine can begin at any age; most commonly attack occurs during teenage years and by 40 years of age $90 \%$ of the affected individuals have had their first attack. Although migraine can begin in older patients it should be viewed with suspicion specially if associated with focal neurological deficit. In ophthalmoplegic migraine neurological deficit may last for an hour to several months [3]. The focal nature of deficit has often led to detailed investigations including carotid angiography to rule out posterior communicating or internal communicating artery aneurysm. Oedema of the vessel wall of the carotid artery in the region of cavernous sinus is one possible explanation for the involvement of cranial nerves in this region [4], however the exact mechanism remains obscure [5]. The prognosis is favourable unless very frequent attacks occur. Palsies of other cranial nerves like trochlear, abducens and first division of trigeminal nerve have been described [6].

\section{REFERENCES}

1. Robertson WC Jr, Schnintzler ER. Ophthalmoplegic migraine in infancy, paediatrics 1978:61:886-8.

2. Symonds C. Migrainous Variants. Trans Med Soc London 4th series 1951;67:237.

3. Crucger MP. Mazow ML. An unusual case of ophthalmoplegic migraine. Am J Ophthalmol 1978;86:414-7.

4. Walter G, Bradley, et al. Neurology in clinical practice 1991:2:1524.

5. Paerce J. The ophthalmological complications of migraine. J Neurol Sci 1968;6:73.

6. Vijayan N. Ophthalmoplegical migraine; Ischaemic or compressive neuropathy? Headache 1980;20:300.

\footnotetext{
Classified Specialist Neurology, ${ }^{+}$Classified Specialist Neurosurgery, Department of Neurosciences, Command Hospital (NC), C/o 56 APO.
} 